

\title{
Better maintenance decision making in business networks with a LCC model
}

\author{
Tiina Sinkkonen ${ }^{1}$; Antti Ylä-Kujala ${ }^{2}$; Salla Marttonen ${ }^{3}$; Timo Kärri ${ }^{4}$ \\ 1tiina.sinkkonen@lut.fi; ${ }^{2}$ antti.yla-kujala@lut.fi; ${ }^{3}$ salla.marttonen@1ut.fi; ${ }^{4}$ timo.karri@lut.fi \\ 1,2,3,4 School of Industrial Engineering and Management, Lappeenranta University of Technology, \\ Lappeenranta, Finland
}

\begin{abstract}
Outsourcing of maintenance operations has created new kind of decision-making situations. These situations require above all increased cost-awareness. Our industrial research partners have noticed in several occasions that there is a need for a common network-level tool which would enable the planning of maintenance operations. Most planning is even today made by each partner's own simple calculations or is based on the empirical knowledge of maintenance experts. Co-operation between the customer and the service provider is still rather uncommon.

This article presents a life-cycle model that helps in planning maintenance operations better than previous models. Most models are very case-specific, suitable only for the item or the purpose of use in question. In many cases the models are quite theoretical and include complicated mathematical solutions, requiring special skills from the user. Usually the models have also been constructed for the needs of asingle company without a network perspective. Our general item level life-cycle model takes into account the point of view of all maintenance network members, it makes planning the future scenarios of maintenance operations together possible, and it provides a practical tool for daily use to reach cost and time savings in the whole network.
\end{abstract}

Keywords-life-cycle model, maintenance, customer, network, service provider, net present value, benefit-cost ratio

\section{INTRODUCTION}

Industrial maintenance outsourcings have changed the basis of maintenance decision making in many companies. When multiple different organizations (e.g. a customer, a service provider and an equipment provider) must collaborate to ensure the availability of production equipment, the decisions cannot be based on the tacit knowledge of individual maintenance experts, as has often been the case in in-house maintenance. Instead, a new kind of transparency is required from the companies operating in maintenance networks, not to mention cost-awareness, which is an essential part of service pricing, contract formulation and maintenance performance measurement.

Maintenance decision making often has to do with the future, especially as regards proactive maintenance: resources are sacrificed to improve the functioning of the items, not just at the moment but also in times to come. Thus maintenance should be approached from the perspective of investment appraisal, and the impacts of the decisions on the whole life cycle of the item should be considered.
A number of life-cycle cost (LCC) models for different kind of products, equipment, machines or systems can be found in the literature [1]-[8]. Although the demand for LCC models is commonly admitted, these models are still often very case-specific, suitable only for the item or the purpose of use in question. There cannot be found a single LCC model that has been widely used and accepted as a standard [4].

Hochchorner and Noring [9] carried out an interview study in 2005-2006 and 2010 among Swedish companies regarding the use of LCC. They noticed that "even though many interviewees believed that LCC can be important for decision making, it was not always performed or used." The reason for this was that LCC was experienced as difficult and complicated to use, and a time-consuming and expensive method to carry out. This result supports the argument of Korpi and Ala-Risku [10], according to whom there is no evidence that LCC models are commonly used. They have also observed that the LCC analysis is often affected by a lack of adequate information. Kayrbekova et al. [6] note that it may be impossible to perform a complete LCC model due to the enormous need of data and information.

The interviewees in the study of Hochchorner and Noring [9] pointed out that there was a real need for a common and easy-to-use LCC model as a decision-making tool. Our industrial research partners, operating either as maintenance service buyers or providers, have noticed also in several occasions that there is a need for a common network-level tool which would enable the planning of maintenance operations. We have created an LCC model to support maintenance decision making in business networks.

The research questions of the paper are the following:

- How does the created life-cycle model differ from or is better than the existing models?

- What are the possible limitations of the model?

This paper contributes to the previous discussion through pointing out the general shortcomings of the existing LCC models in maintenance. We also describe the design and costing principles used in constructing our general item-level LCC tool for network-level maintenance decision making, and finally explicate the limitations and challenges that still remain unsettled and should thus evoke further research.

After this introduction section, section II concentrates on the comparison between the existing models and our model by 
using the five-step method of LCC. Next, section III introduces the mathematical structure of our LCC model for an industrial maintenance network. In section IV the limitations and challenges of our LCC model are discussed. The article finishes with conclusions in section $\mathrm{V}$.

\section{LIFE-CYCLE COSTING PROCESS}

Originally, the LCC has been seen as a tool for estimating the acquisition cost of a product from design to disposal. Nowadays the LCC can be used in various situations, like managing the costs, planning the future or organizing the actions in the long run [11].

Life-cycle costs mean typically the costs which arise from owning, utilization, maintenance and disposal of a product, item, project or system [12], [13]. As the main focus in analysing different kinds of LCC methods is usually on costs, when speaking of comprehensive LCCs, the profits must also be included. The life-cycle profits (LCP) are the profits the company gains during the whole life-cycle period of the product, item or service [14]. Indounas [15] has pointed out that the price is the only way to get profit. This is true when we think of the equipment provider or service provider, but the customer on the other hand gets profit for example through rationalization or better reliability [16].

Many models and methods for describing the LCC have been developed. For example the standards for life-cycle costs present calculation processes including four to seven main stages [17], [18]. Several alternatives for designing the LCC process can be found in the literature [19] - [21]. Figure 1 shows a five-step method for the LCC, adapted from Woodward [19] and Kawauchi \& Rausand [21].

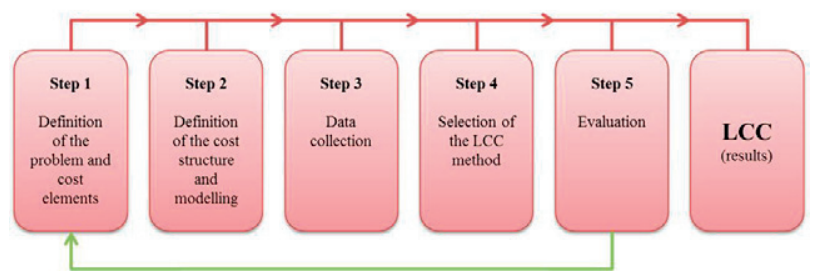

Fig. 1. Five steps of LCC (adapted from Woodward [19] and Kawauchi \& Rausand [21])

The following chapters concentrate on comparing the existing models with our model by using the five-step method of LCC presented in figure 1.

\section{A. Step 1: Definition of the problem and cost elements}

Step 1 defines the problem and the cost elements needed. This means specifying the wideness and target of the model. It also includes a description of the cash flow along the life cycle. This step is important for the success of the final accounting process, although it may be very challenging to identify the cash flow in many cases [19], [21].

Seven recent academic studies from years 2006 - 2012 presenting LCC models including maintenance, have been mainly constructed to contain costs along the whole life cycle, designed only for the item in question and from the perspective of one company [1] - [7]. Our general item-level life-cycle model takes account of the point of view of all maintenance network members, i.e. the customer, service provider and equipment provider.

Our model focuses on the life cycle of the item based on the maintenance contracts. This life cycle can vary depending on the role of the network member. The length of the life-cycle period of the item for the equipment provider may be for example ten years, but at the same time the customer company may have two to three different contracts with the maintenance service provider. During the life cycle of the item, the cash flows to be included in the model include e.g. the network members' maintenance costs, revenues from equipment and service sales, and performance-related bonuses and penalties.

\section{B. Step 2: Definition of the cost structure and modelling}

Step 2 is definition of the structure of the model and the cost categories to be used. There are many ways to classify the costs, but it must be done so that the company can make a comparison between the selected products or services on a sufficient level. The costs can be categorized for example by design, research and development, production, implementation, and utilization [19], [21].

Jun and Kim [2] have only three main cost categories in their LCC model; investment, annual operation and maintenance, and disposal costs. Waghmode and Sahasrabudhe [4] have included 25 different cost elements in their LCC model, whereas Lapašinskaite and Boguslauskas [3] have paid most attention only to operational and maintenance costs.

There are six cost categories in our model; operational maintenance, quality, outsourcing and logistics, environmental, asset management, and other costs. These main cost categories (e.g. operational maintenance costs) are then further divided to subcategories like labour, material or energy. The original cost structure was developed together with companies working in the forest industry and it was then specified in co-operation with maintenance experts [22] - [24]. Although our model contains a number of subcategories for costs, using them is optional in order to increase the generalization of the tool. If the accumulated cost data is not specific enough, or if the company feels that breaking down the costs will not bring any specific additional value to them, they are free to use even one single cost category.

All recent LCC models [1] - [7] consider the costs only from the point of view of the user. Our model is made for a maintenance network. It is a tool for planning the operations together with a customer (buyer of maintenance services), a maintenance service provider and an equipment provider, who supplies the equipment and maybe also equipment-related services to the customer.

\section{Step 3: Data collection}

Step 3 is collecting all the data required. This step has the great impact on the final results. The initial data must be reliable and as relevant as possible [19], [21]. This has been a very challenging stage for us as well, because it is very difficult to acquire adequate maintenance cost data at the item or operational level. There are a lot of cost data in companies' cost systems, but the information is not detailed enough. Production-related information such as capacity, operating time, production speed etc. is well known, and also 
maintenance-related information like maintenance hours and the share of corrective or preventive maintenance can be found easily. However, product-related information can be problematic, because the item in question may not produce finished products but semi-finished products or parts of the finished product. In these situations it is challenging to define for example the unit production cost or profit margin. This problem will disappear when the perspective is expanded to the production line or even larger entities.

The network-level view is beneficial also from the perspective of data collection. The life-cycle data of the item can be fragmented between different network partners, and pooling the data with a joint decision-making tool can result in valuable information for each company.

\section{Step 4: Selection of the LCC method}

The method for life-cycle accounting is chosen in step 4 . The model must be suitable for analysing the costs of the product or service in question. This stage includes also the actual calculation.

In life-cycle cost analysis, the cost elements will occur at different times throughout the life of the item. Thus, it is essential to calculate the present value of the life-cycle costs. The future costs can be discounted to the present value by using a specific discount rate [19]. The present value can be seen as a good evaluating method when discounted cash flows are concerned [25] - [27]. For example Jun and Kim [2], Waghmode and Sahasrabudhe [4], Lapašinskaitè and Boguslauskas [3], and Lad and Kulkarni [1] use the present value to calculate the LCC.

Kayrbekova et al. [6] introduce activity-based LCCs in their research. This technique observes the overhead costs and allocates them more accurately than conventional cash flow oriented costing. It also highlights the cause-and-effectrelationships of the costs. Korpi and Ala-Risku [10] remind that using the activity-based method requires an extensive activity-cost database.

We have developed our model based on the conventional cash flow -oriented model by using the present value to calculate the LCC. These choices make it possible to keep the model simple to implement and easy to use. The decision of not to apply the activity-based LCC is justified in terms of model generalization, as a vast majority of companies do not have the needed activity-related data available.

\section{E. Step 5: Evaluation}

Step 5 is for analysing the LCC results, estimating the whole calculation process and sensitivity analyses. It is possible to analyse the changes of the important factors and their impact for the final results. It is also possible to move back to step 1 and change the initial data if necessary [19], [21]. Jun and Kim [2] emphasise the importance of sensitivity analysis when there are uncertainties in the input data.

Our LCC model results in the cumulative net present value of maintenance as well as in the maintenance benefit-cost ratio for each network member. For years now the academic discussion on maintenance has emphasized the fact that in order to convince the decision makers, the results of maintenance analysis should be translated into economic aspects. This is what we have done, trying to offer maintenance managers a tool for validating their decisions to the managers at the top levels of organizational hierarchy. In addition, the results of our model enable network-level performance measurement and management. However, sharing the economic results outside the company borders requires a considerable amount of trust and work from the partners, and is thus not often put into practice.

\section{OUR NETWORK LEVEL LCC MODEL}

In this section, the structure of our life-cycle cost model as a planning tool for an industrial maintenance network is presented. The developed model focuses on the maintenance operations and their costs and effects at the network level. The objective has been to create a common tool for planning to gain benefit for each member by increasing the value of the whole network.

The life-cycle model is defined as the summation of three cost components; maintenance costs, maintenance cost savings and maintenance profit loss or gain. In addition, the maintenance profit loss or gain, closely connected to the maintenance of the equipment itself, is substituted with certain profit categories, such as contract-based profits, in the case of the service provider or equipment provider, as the equipment is owned by the customer.

The model focuses on maintenance, because its costs, savings and profits dominate along the whole life-cycle of the item in many cases [3], [4].

Figure 2 illustrates the design and costing principles of our model. The input data is on the left of the figure, the costing principles in the middle and the results on the right. 


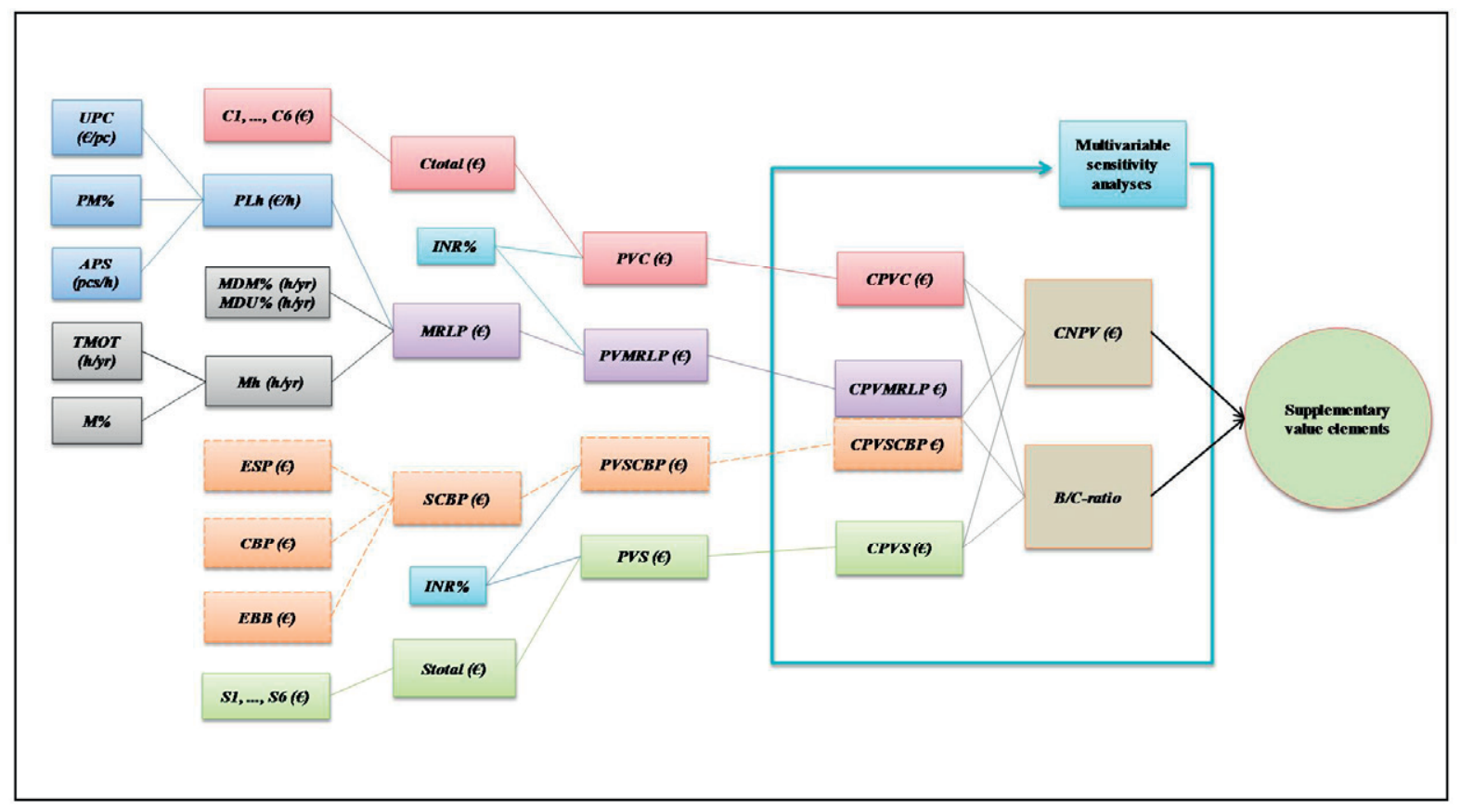

Fig. 2 LCC model for a maintenance network (the abbreviations are explained in the sections below)

\section{A. Annual Maintenance Costs}

The annual maintenance costs in total, $C_{\text {total }}$, can be calculated by summing up the six subcategories of the costs (1).

$$
C_{\text {total }}=C_{1}+C_{2}+C_{3}+C_{4}+C_{5}+C_{6}
$$

where

$$
\begin{aligned}
& C_{1}=\text { operational maintenance costs } \\
& C_{2}=\text { quality costs } \\
& C_{3}=\text { costs of outsourcing and logistics } \\
& C_{4}=\text { environmental costs } \\
& C_{5}=\text { asset management costs } \\
& C_{6}=\text { other costs }
\end{aligned}
$$

These six subcomponents of the costs are based on the definition of the cost structure for maintenance services made by the researcher [22]. Some of the original cost categories have been left out during the development of the model due to the reserved feedback of maintenance experts.

The operational maintenance costs, $C_{l}$, consist of labour, energy and material costs. The quality costs, $C_{2}$, include quality control costs and disposal and processing costs of low-grade products. The costs related to outsourcing and logistics are marked as $C_{3}$. The environmental costs, $C_{4}$, are the sum of cleaning, processing and supervision costs. The costs of current assets and the costs of fixed assets form asset management costs, $C_{5}$. The other costs, $C_{6}$, are composed of costs like tools and instruments, research and development, training and negotiation, as well as the costs of occupational safety and accidents. There is, however, a couple of exceptions to this categorization. First of all, the quality costs include warranty costs instead of the abovementioned ones for the service providers and equipment providers in the model. Also research and development form a separate cost category to these two actors, including both designing costs and data acquisition costs.

\section{B. Annual Maintenance Cost Savings}

Annual maintenance cost savings, $S_{\text {total }}$, consist of six sub components (2) which are based directly on cost information entered by the user. For example $S_{l}$ is the operational cost savings.

$$
S_{\text {total }}=S_{1}+S_{2}+S_{3}+S_{4}+S_{5}+S_{6}
$$

Modelling the annual cost savings is based on the comparison of the average costs of the life-cycle so far to the annual costs of the present year. Thus occasional large variation in yearly costs can be eliminated and they do not have too much influence on planning the future operations. Equation (3) presents the annual subcomponent of maintenance cost saving.

$$
S_{1}=\left(\sum_{n=1}^{k} C_{1_{n}}\right) / k-C_{1_{k}}
$$


where

$S_{I}=$ operational maintenance cost savings based on input data of operational costs

$k=$ length of the planning period, including both history and future years

The other five cost saving subcategories from $S_{2}$ to $S_{6}$ are calculated the same way as $S_{l}$ above.

\section{Annual Maintenance Profit Loss or Gain}

Maintenance-related profits and losses illustrate the financial effects of maintenance changes. This can be calculated by the profit losses due to one hour stoppage in production, $P L h$, and maintenance hour, $M h$. Profit losses caused by one hour stoppage in production, $P L h$, is calculated by multiplying the production costs per unit, $U P C$, profit margin ratio, $P M \%$, and production speed on average, $A P S$ (4).

$$
P L h=U P C \cdot P M \% \cdot A P S
$$

The annual maintenance hours, $M h$, consist of maintenance stoppages, maintenance performed during on-going manufacturing and maintenance executed during other production stoppages. This means stoppages during which no actions are done with the machine. However, underutilization is not included in the number. Mh.

Equation (5) represents the annual maintenance hours,

$$
M h=T M O T \cdot M \%
$$

where

$T M O T=$ theoretical maximum operating time

$M \%=$ share of maintenance of maximum operating time

The theoretical maximum operating time, TMOT, is the absolute maximal number of hours in a year that the equipment could be run in an ideal situation. For example, when the equipment is continuously in use, the theoretical maximum operating time is $24 \mathrm{~h} \cdot 365=8760 \mathrm{~h}$. The share of total maintenance of maximum operating time, $M \%$, is the percentage of different maintenance operations in relation to the annual operating time maximum. This percentage includes both corrective and preventive maintenance.

The lost profits caused by maintenance operations are constructed in a way that only maintenance-related stoppages are taken into the calculations. Maintenance operations executed during manufacturing without a stoppage and maintenance carried out during other stoppages than maintenance-related ones, are not included either, because they do not add to losses from maintenance.

The annual maintenance profit loss or gain in relation to the life-cycle average, $M R P L$ is

$$
M R P L=[M h-(M D M \% \cdot M h+M D U \% \cdot M h)] \cdot P L h
$$

where

$$
\begin{gathered}
M D M \%=\text { share of maintenance performed during } \\
\text { manufacturing } \\
M D U \%=\begin{array}{c}
\text { share of maintenance performed during } \\
\text { underutilization }
\end{array}
\end{gathered}
$$

$M R P L$ is for the customer. The profit of the service provider or equipment provider is called $S C B P . S C B P$ is a sum of contract-based profits, $C B P$, equipment-based bonuses, $E B B$, and equipment sales-based profits, $E B P(7)$.

$$
S C B P=C B P+E B B+E B P
$$

The contract-based profits, $C B P$, are understood here widely, as all those payments/profits that belong to the service provider are based on maintenance contracts. The equipment-based bonuses, $E B B$, are extra profits/incentives that the service provider or equipment provider gets only under certain circumstances, such as meeting key indicators. For example, a bonus is granted when the utilization rate goes over 90 percent. This potential bonus can also be dependent on certain steps $(90$ percent $=$ bonus amount, 95 percent $=2 \mathrm{x}$ bonus amount) in order to give extra motivation to the one taking care of maintaining the equipment. The equipment sales-based profits, ESP, include only those profits that originate directly from equipment sales to the customer. Thus, this category is only available for the equipment provider. The contract-based profits should not be entered here.

\section{Cumulative Net Present Value of Maintenance Profits}

The first key figure of the life-cycle model is the cumulative net present value. The cumulative net present value of maintenance profits, $C N P V$, is a sum of the cumulative present value of maintenance costs, $C P V_{C}$, cost savings, $C P V_{S}$, and profit loss or gain, $C P V_{M R P L}$.

Equation (8) presents the cumulative net present value of maintenance profits, $C P N V$

$$
C N P V=\left(C P V_{S}+C P V_{M R P L}\right)-C P V_{C}
$$

The first part of the equation of the $C N P V$ is a sum of the present values of the annual cost savings, $C P V_{S}$, throughout the planning period (9).

$$
C P V S=\sum_{n=1}^{k}\left(\frac{1}{(1+i)^{n}} \cdot S_{\text {total }_{n}}\right)
$$

The second part of the equation of the $C P N V$ is a sum of the present values of the annual profit loss or gain, $C P V_{M R P L}$, along the planning period (10).

$$
C P V_{M R L P}=\sum_{n=1}^{k}\left(\frac{1}{(1+i)^{n}} \cdot M R L P_{\text {total }_{n}}\right)
$$


The third factor of the equation of the $C P N V$ is a sum of the present value of the annual maintenance costs, $C P V_{C}$, throughout the planning period.

$$
C P V_{C}=\sum_{n=1}^{k}\left(\frac{1}{(1+i)^{n}} \cdot C_{\text {total }_{n}}\right)
$$

It is possible to estimate the maintenance profits of the whole planning period by the cumulative net present value with a specific discount rate.

The cumulative net present value expresses the maintenance surplus, or alternatively the maintenance deficit over the chosen planning period in the model. Therefore, the $C N P V$ is an excellent indicator that ultimately clarifies the point where the profits exceed the costs within the item's life-cycle. Naturally, it is possible that this kind of a "breaking point" does not exist and thus the $C N P V$ can also be used to find an acceptable level for the deficit and maintain it.

\section{E. Benefit-Cost Ratio}

The second key figure of the life-cycle model is the benefit-cost ratio (12). It can be seen annually what the proportion of maintenance profits is in the maintenance costs. The figure benefit-cost ratio describes in practice what the multiple maintenance profits are in comparison with the maintenance costs. The benefit-cost ratio should always get the value of over 1 , because then the profits overrun the costs.

$$
B / C-\text { ratio }=\frac{\left(C P V_{S}+C P V_{M R P L}\right)}{C P V_{C}}
$$

The benefit-cost ratio is a suitable indicator for analysing the balance between costs and profits. It is important to find the optimal balance between the maintenance costs and maintenance losses, but it is also important not to focus too much on optimizing the maintenance actions, because it may lead to a situation where the costs of item maintenance are bigger than the received profits.

\section{F. Sensitivity analyses}

In our model it is possible to analyse the changes of the important factors and their impact on the final results (cumulative net present value and benefit-cost ratio) by using sensitivity analysis. The user can decide which input factor share of maintenance of maximum operating time, cost element, production speed on average or interest-rate, is critical and what are the effects to the calculation if this factor changes for example $\pm 10 \%$ from the planned.

\section{G. Value-elements}

The user can choose one to five important value elements and weight the elements based on his perspective and thoughts in this particular maintenance service case. The model gives numerical values to the value elements, which can be then used as a basis for contracts and bonus systems between the network members.

\section{LIMITATIONS OF OUR LCC MODEL}

The model has been developed in close cooperation with maintenance experts from eight different companies representing a customer, service provider and equipment provider. These experts have tested the model and given us useful information and feedback to improve the model so far, but there are still some shortcomings in the model. Some of these weaknesses, limitations and targets for further development are listed below.

- Existing market conditions should be acknowledged in relation to the theoretically lost production that causes lost profits in the model. At the moment all stoppages are treated as a lost profit although the production cannot be sold. This can be eliminated in the model by decreasing the theoretical maximum operating time.

- Eliminating the present correlation of the increased production speed and the increased profit losses by taking gained revenues into account. The model works like that at the moment.

- Taking alternative or reduplicate production options and buffer stocks into account when determining the maintenance costs in the model. The model does not take into account the effect of the sale on the maintenance. The errors of maintenance lead to lost production, but improved maintenance does not raise the profits. This is already an option in the model, but it is not linked to the components of lost production.

- Enabling the entering of start-up and shutdown times of an item to the model, as the production speed may be reduced in these cases. At the moment these are left out, because the idea was to develop a generallevel model, and considering the costs along the whole life cycle, these are trivialities.

- Protecting confidential information throughout the worksheets of the value-based life-cycle model should be rigorously considered. At the moment all input data is shown to all network members.

- The entire value-thinking should be altered. At the moment we have decided to speak only for increased total value of the network (equals CNPV). Value distribution into the single elements will be left out of our LCC model, because the current division of the value by weighted value elements is quite artificial. However, the value elements are still useful for negotiations and contracts between the members of the maintenance network.

The first three improvements on the list, related to the calculation of the maintenance-related profit losses will most likely be included in the third version of the model, as these aspects have somewhat substantial influence on the main results. The aim is to develop the general-level and simple model, and therefore some facts for special lines of business must be left out. 
There are still some limitations in applying our model in different industries and contexts. The network perspective brings additional challenges related to information confidentiality. In addition, the results of the model should be integrated better to comprehensive maintenance performance measurement, taking intangible value elements into account. These limitations represent logical topics for further research.

The value elements and the distribution of value will be realised with an additional model called value analyser, which will probably be connected to the LCC model. These two models together complement each other in such a way that LCC model presents the hard side of the value thinking, and the value analyser the soft side.

\section{CONCLUSIONS}

In this paper we have shed light on the construction process of a general LCC model for maintenance planning at the network level. Compared to the existing LCC models in maintenance, we have made the improvements described in Table I.

Table 1. Comparison of the characteristic of previous LCC models and the created model.

\begin{tabular}{|c|c|}
\hline $\begin{array}{c}\text { Characteristics of previous } \\
\text { models }\end{array}$ & $\begin{array}{c}\text { Characteristics of the created } \\
\text { model }\end{array}$ \\
\hline Case-specific & Pursuing generalization \\
\hline The perspective of one company & $\begin{array}{c}\text { The perspective of a company } \\
\text { network or one company }\end{array}$ \\
\hline $\begin{array}{c}\text { Life-cycle profits are not always } \\
\text { included }\end{array}$ & $\begin{array}{c}\text { Life-cycle profits are included and } \\
\text { customized for each network } \\
\text { member }\end{array}$ \\
\hline $\begin{array}{c}\text { Various different sets of cost } \\
\text { categories, depending on the case } \\
\text { and on the model }\end{array}$ & $\begin{array}{c}\text { Various cost categories in the same } \\
\text { model, the user can decide on how } \\
\text { to apply them }\end{array}$ \\
\hline $\begin{array}{c}\text { Data collection poses challenges } \\
\text { for each user individually }\end{array}$ & $\begin{array}{c}\text { Collaboration in data collection is } \\
\text { enabled through a joint tool }\end{array}$ \\
\hline $\begin{array}{c}\text { LCC methods depend on the case; } \\
\text { some could be generalized, some } \\
\text { not }\end{array}$ & $\begin{array}{c}\text { Conventional cash flow and present } \\
\text { value chosen as LCC methods to } \\
\text { increase applicability }\end{array}$ \\
\hline $\begin{array}{c}\text { Sensitivity analyses and } \\
\text { economically justified results are } \\
\text { often used }\end{array}$ & $\begin{array}{c}\text { Sensitivity analyses, economically } \\
\text { justified results and the possibility } \\
\text { for network-level performance } \\
\text { management }\end{array}$ \\
\hline
\end{tabular}

The theoretical contribution of the paper includes pointing out the limitations of previous research on LCC modelling in maintenance. We have suggested a model to overcome a number of these limitations, and we have presented the design and costing principles of our model in a transparent way to enable feedback, discussion and iteration. Our model still has a number of shortcomings, which indicate possible research gaps for the academia. Our managerial implications include discussion on the process and mathematics of constructing a general model to support decision making in maintenance. Hopefully this paper will challenge companies to use LCC modelling in maintenance planning, both at the company and network level.

\section{REFERENCES}

1] B. K. Lad and M. S. Kulkarni, "Optimal maintenance schedule decisions for machine tools considering the user's cost structure", International Journal of Production Research, Vol. 50, No. 20, pp. 5859-5871, 2012.
[2] H.K. Jun, and J.H. Kim, J.H., "Life Cycle Cost Modeling for Railway Vehicle", International Conference on Electrical Machines and Systems, October, 8-11, 2007, Seoul, Korea.

[3] R. Lapašinskaitè, and V. Boguslauskas, "Non-Linear Time-Cost Break Even Research in Product Lifecycle", Engineering Economics. nro 1, pp. 7-12, 2006

[4] L.Y. Waghmode, and A.D. Sahasrabudhe, "Modelling maintenance and repair costs using stochastic point processes for life cycle costing of repairable systems", International Journal of Computer Integrated Manufacturing, Vol. 25, No. 4-5, pp. 353-367, 2012.

[5] Z. Wang, and X. Xu, "SVLC: Service value life cycle model", IEEE International Conference on Cloud Computing. September 21-25, Bangalore, pp. 159-166, 2009.

[6] D. Kayrbekoya, T. Markeset, and B. Ghodrati, "Activity-based life cycle cost analysis as an alternative to conventional LCC in engineering design", International Journal of Systems Assurance Engineering and Management, Vol. 2, No. 3, pp. 218-225, 2011

[7] A. Navarro-Galera, and R.I. Ortúzar Maturana, "Innovating in defence policy through spending efficiency: The Life Cycle Costing Model", Journal of Policy Modeling, Vol. 33, No. 3, pp. 407-425, 2011.

[8] L. A. Ferreira, J. Sobral, and J. T. Farinha, "LCC - Life Cycle Cost, its relevance to Physical Asset Management", EuroMaintenance 2014, Congress proceedings, May 5-7, Helsinki, Finland, 2014.

[9] E. Hochschorner, and M. Noring, "Practitioners'use of life cycle costing with environmental costs - a Swedish study", International Journal of Life Cycle Assessment, Vol. 16, No. 8, pp. 897-902, 2011.

[10] E. Korpi, and T. Ala-Risku, "Life cycle costing: a review of published case studies", Manag Audit J 23(3):240-261, 2008

[11] A. Lindholm, and P. Suomala, "Learning by costing - Sharpening cost image through life cycle costing?", International Journal of Productivity and Performance Management, Vol. 56, No. 8, pp. 651$672,2007$.

[12] H.P. Barringer, A Life Cycle Cost Summary, International Conference of Maintenance Societies. May, 20-23, 2003, Perth, Australia, 2003

[13] Y. Asiedu, and P. Gu, "Product life cycle cost analysis: state of the art review", International Journal of Production Research, Vol. 36, no. 4, pp. 883-908, 1998

[14] L. Hagberg, S. Hautanen, T. Henriksson, H.S. Laine, E. Löppönen, and E. Riikonen, Käynnissäpidon johtaminen ja talous, Rajamäki, KP-Tieto, p. 224, ISBN 951-97101-2-4, 1996.

[15] K. Indounas, "Successful industrial service pricing", The Journal of Business \& Industrial Marketing. Vol. 24, no. 2, pp. 86-97, 2009.

[16] S. Huber, and S. Spinler, "Pricing of full-service repair contracts", European Journal of Operational Research, Vol. 222, no. 1, pp. 113 $121,2012$.

[17] NORSOK O-CR-002, Life Cycle Cost for Production Facility, Norwegian Technology Standards Institution, p. 35, 1996.

[18] EN ISO 15663-1, Petroleum and natural gas industries - Life cycle costing - Part 1: Methodology, 1st edition, Brussels, European Committee for Standardization, p. 17, 2000.

[19] D.G. Woodward, "Life cycle costing - theory, information acquisition and application", International Journal of Project Management. Vol.15, No. 6, pp. 335-344, 1997.

[20] H.P. Barringer, and D.P. Weber, Life Cycle Cost Tutorial. The 5th International Conference on Process Plant Reliability. October 2-4, Houston, Texas, p. 58, 1996

[21] Y. Kawauchi, and M. Rausand, "Life Cycle Cost (LCC) analysis in oil and chemical process industries", Norwegian University of Science and Technology, Trondheim, Norway, 1999

[22] T. Sinkkonen, S. Marttonen, L. Tynninen, and T. Kärri, "Modelling costs in maintenance networks", Journal of Quality in Maintenance Engineering, Vol. 19, No. 3, pp. 330-344, 2013

[23] T. Sinkkonen, H. Kivimäki, S. Marttonen, and T. Kärri, "A valuebased life-cycle framework for networks of industrial maintenance service", The 26th International Conference on Competitiveness 
Through Maintenance and Asset Management, June, 11-13, 2013, Helsinki, Finland.

[24] H. Kivimäki, T. Sinkkonen, S. Marttonen, and T. Kärri, "Creating a life-cycle model for industrial maintenance networks", Proceedings of the Maintenance Performance Measurement and Management, Conference 12th - 13th September, 2013, Lappeenranta, Finland, ISBN 978-952-265-443-4, 2013

[25] P. Baily, D. Farmer, D. Jessop, and D. Jones, Purchasing Principles and Management. 9th edition. Harlow. Financial Times Prentice Hall. p. 427 ISBN 0-273-64689-3, 2005.

[26] C.T. Horngren, S.M. Datar, and G. Foster, Cost Accounting: A Managerial Emphasis, 12th edition, Upper Saddle River, New Jersey. Prentice Hall, p. 868, ISBN 0-13-149538-0, 2006.

[27] J.F. Oehmke, "Anomalies in net present value calculations", Economics Letters. Vol. 67, no. 3, pp. 349-351, 2000. 